DE92 018239

\title{
GRAIN BOUNDARY TRANSPORT AND RELATED PROCESSES \\ IN NATURAL FINE GRAINED AGGREGATES
}

\author{
Report of Progress
}

for Period August 15, 1991 to August 15, 1992

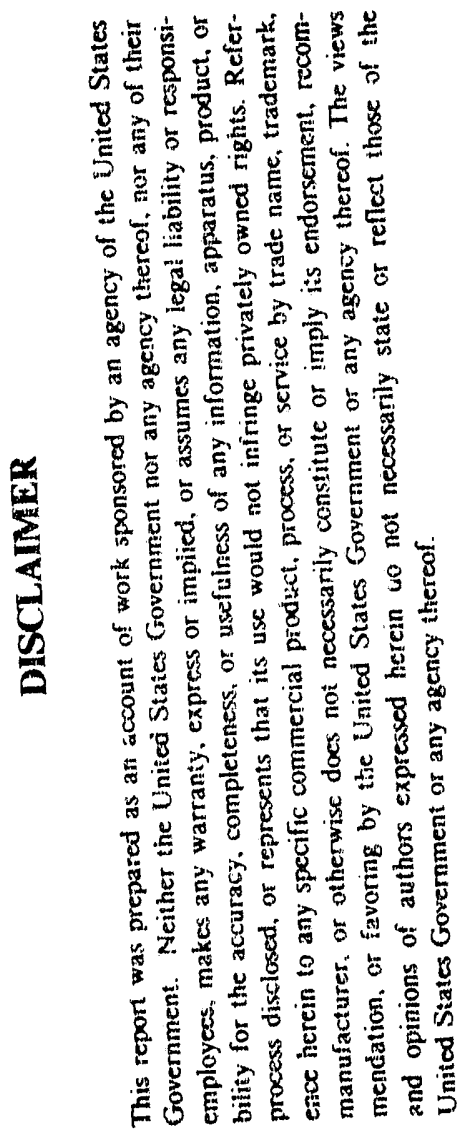

R. A. Yund and J. R. Farver

\author{
Brown University \\ Departmen of Geological Sciences \\ Providence, RI 02912
}

428.64

July' 1992

Prepared for

THE U.S. DEPAR'TMENT OF ENERGY

AGREEMENT NO. DE-FG()2-90ER 14144 


\title{
NOTICE
}

This report was prepared as an account of work sponsored by the United States Government. Neither the United States nor the Department of Energy, nor any of their employees, nor any of their contractors, subcontractors, or their employees, makes any warranty, express or implied, or assumes any legal liability or responsibility for the accuracy, completeness, or usefulness of any information, apparatus, product or process disclosed or represents that its use would not infringe privately-owned rights.

Report of Progress for the period August 15, 1991 to August 15, 1992:

Grain Boundary Transport and Related Processes in Natural Fine Grained Aggregates

R. A. Y'und and J. R. Farver

\begin{abstract}
We are pleased to report that all of the original research objectives will be realized by the end of the project period. In summary, we have developed a new tecinnique for measuring grain boundary diffusion rates in polycrystalline aggregates and have successfully employed this technique to determine oxygen grain boundary diffusion rates in natural fine-grained quartz aggregates (novaculites) over a wide range of temperatures (Farver and $Y$ und, 199(); Farver and Yund, 1991a). In addition, we have demonstrated the major role of fluid cconposition on the microstructure and oxygen bulk diffusivity in a novaculite sample (Yund and Farver, 1990); Farver and $Y$ und, 1992). Most recently, we have successfully produced hot-pressed fine-grained monomineralic quartz and feldspar aggregates and have measured oxygen grain boundary diffusion rates in these aggregates for comparison to the natural novaculite samples (Farver and Yund, 1991b). Details of these results follow.
\end{abstract}

\section{Oxygen Grain Boundary Diffusion in Fine-Grained Quartz Aggregates}

Oxygen grain boundary diffusion rates have been measured in two fine-grained quartz aggregates (Arkansas novaculite) with 1.2 and $4.9 \mu \mathrm{m}$ diameter grains. SEM and TEM observations show that both samples have equilibrium microstructures consisting of equant grains with triple grain junctions that meet at $\sim 120^{\circ}$. In addition, the grain boundaries are very tight with physical widths on the order of $\leq 10 \mathrm{~nm}$. Samples were annealed hydrothermally at $450^{\circ}$ to $800^{\circ} \mathrm{C}$ and $100 \mathrm{MPa}$ confining pressure using $98 \%{ }^{18} \mathrm{O}$ enriched water. Profiles of $18 \mathrm{O} /\left({ }^{18} \mathrm{O}+16 \mathrm{O}\right)$ with depth from the surface were measured using an ion microprobe. Data are collected from a $68 \mu \mathrm{m}$ diameter circle centered on a rastered area 150-200 $\mu \mathrm{m}$ on a side. Hole depths are measured using an optical interferometer. By collecting data from an area much larger than the grain size of the 
sample, diffusion along many individual boundaries is averaged to yield a representative value for grain boundary diffusion in the sample.

Using graphical solutions appropriate to the boundary conditions employed, and knowing the volume diffusion coefficient, the product of the grain boundary diffusion coefficient ( $\left.D^{\prime}\right)$ and effective boundary width $(\delta)$ is calculated. The value of $D^{\prime} \delta$ is independent of the grain size, geometry and grain boundary tortuosity. An Arrhenius plot (Fig. 1a) of the data yields straight lines for both the 1.2 and $4.9 \mu \mathrm{m}$ grain size samples and the Arrhenius parameters are: $D_{j} \delta=2.6$ and $3.4 \times 10^{-17} \mathrm{~m}^{3} / \mathrm{s}$, and activation energy $(Q)=27 \pm 1$ and $26 \pm 3 \mathrm{kcal} / \mathrm{mol}$, respectively. The activation energy of both samples, $\sim 27 \mathrm{kcal} / \mathrm{mol}(113 \mathrm{~kJ} / \mathrm{mol})$, is significantly less than that for volume diffusion of oxygen in quartz, but greater than that for ionic diffusion in a static fluid. Measured D's values are within the range of values reported from theoretical considerations and field observations as well as experimentally determined lamellar boundary diffusion of oxygen in perthite. Assuming an effective grain boundary width of $\sim 10 \mathrm{~nm}$, the measured oxygen grain boundary diffusion is 3 to 4 orders of magnitude greater than oxygen volume diffusion in quartz and $\sim 5$ orders of magnitude less than ionic diffusion in a static fluid over the temperature range of the experiments.

\section{The Role of Fluid Composition on Microstructure and Oxygen Grain Boundary Transport in Fine-Grained Quartz Aggregates}

Oxygen grain boundary and bulk diffusion rates have been measured in the $1.2 \mu \mathrm{m}$ grain size quartz aggregate (Arkansas novaculite) described above, after anneals with wetting and nonwetting fluids, to determine the effect of microstructure on oxygen grain boundary diffusion rates. Samples were annealed at $800^{\circ} \mathrm{C}$ and $150 \mathrm{MPa}$ confining pressure for 6 to 12 days with pure $\mathrm{CO}_{2}$, pure $\mathrm{H}_{2} \mathrm{O}$, or $\mathrm{H}_{2} \mathrm{O}+\mathrm{NaCl}(\sim 6 \mathrm{M})$ to produce new equilibrium microstructures. The pure $\mathrm{CO}_{2}$ and pure water fluids produced non-wetted structures $\left(\theta>60^{\circ}\right)$; samples annealed in pure $\mathrm{CO}_{2}$ showed no changes, and samples annealed in pure water showed minor changes, including the formation of small pores at many of the triple grain junctions. In contrast, the water $+\mathrm{NaCl}$ fluid produced a wetted microstructure $\left(\theta<60^{\circ}\right)$ with large pores at essentially all of the triple junctions. These microstructures are consistent with the wetting behavior of the se fluids for quartz aggregates as reported by other workers.

After the textural equilibration anneals, the samples were annealed at $800^{\circ}$ to 45()$^{\circ} \mathrm{C}$ and 100 MPa confining pressure with $98 \%{ }^{18} \mathrm{O}$-enriched water to determine the grain boundary diffusion rates. The short duration and lower temperature of the diffusion anneals produced no further changes in the microstructures. Profiles of $18 \mathrm{O} /(18 \mathrm{O}+16 \mathrm{O})$ with depth from the surface were measured using an ion mic:oprobe, and the product of the grain boundary diffusion coefficient (D') and effective boundary width $(\delta)$ determined. Compared to the starting material, the D' $\delta$ values for samples texturally equilibrated with pure $\mathrm{CO}_{2}$ and pure water are about the same and about four times greater, respectively. The D' $\delta$ values for samples texturally equilibrated with $6 \mathrm{M}$ 
$\mathrm{NaCl}$ are three to four orders of magnitude greater than that for the starting material. In addition, the $D^{\prime} \delta$ value for a sample texturally equilibrated first with $6 \mathrm{M} \mathrm{NaCl}$ and then with pure $\mathrm{CO}_{2}$ is about a factor of three greater than the value for the starting material, demonstrating that textural equilibration is reversible.

The results of this study indicate that grain boundary transport rates in quartz aggregates are strongly influenced by the microstructure which, in turn, depends on fluid composition. In nonwetted samples, changes in grain boundary structure or the formation of small isolated pores at triple junctions can change $D^{\prime} \delta$ values by changing $\delta$. However, this effect is minor compared to the change in D' $\delta$ values for samples with non-wetted versus wetted microstructures. The much faster rates for wetted samples are believed due to oxygen transport (probably in the form of molecular water) along the interconnected channels by ionic diffusion in a static fluid. The connected porosity in the wetted sample is $<1 \%$ of the total porosity, a result which is consistent with estimates from natural contact zones.

\section{Oxygen Grain Boundary Diffusion in Hot-Pressed, Fine-Grained Monomineralic Quartz and Feldspar Aggregates}

The above technique that we have used for measuring grain boundary diffusion rates in polycrystalline aggregates requires fine grain size $(<10 \mu \mathrm{m})$ material to eliminate grain boundary cracking. This constraint greatly limits the availability of natural samples, prompting us to hot* press fine-grained aggregates. We have begun with quartz which can be directly compared to the natural novaculites, and with alkali feldspars which afford the possibility of determining grain boundary diffusion rates for cations as well as oxygen in a geologically important mineral. The quartz aggregates were prepared using sized 1-3 $\mu \mathrm{m}$ diameter fragments of a natural quartz from US Silica (supplied by B. Evans). The albite aggregates were prepared using $2-4 \mu \mathrm{m}$ sized fragnents of a natural albite $\left(\mathrm{NaAlS}_{3} \mathrm{O}_{8}\right)$ and the orthoclase aggregates were prepared using $2-4$ $\mu \mathrm{m}$ sized particles of 'orthoclase' $\left(\mathrm{KAISi}_{3} \mathrm{O}_{8}\right.$ ) glass from Corning (supplied by $\mathrm{R}$. Cooper). All of the samples were vacuum dried at $250^{\circ} \mathrm{C}$ before hor-pressing at 90()$^{\circ}(\mathrm{Qtz}), 1060^{\circ}(\mathrm{Ab})$ or $1100^{\circ} \mathrm{C}$ (Or) and 1.5 GPa, for 5 hours (Qtz) or 20-24 hours (Ab and Or). Grain-scale cracking was essentially eliminated by packing the sealed samples in $\mathrm{NaCl}$ and $\mathrm{cos}$ ling at $3^{\circ} \mathrm{C} /$ minute along with slow decompression. TEM examination of the quartz aggregate indicates a microstructure similar to the novaculites with some porosity $(<1 \%)$ located at three-grain junctions. The albite aggregate has some porosity $(<1 \%)$ because the lath-shaped fragments do not pack well, but most grain boundaries are 'tight' ( $<10 \mathrm{~nm}$ ). The orthoclase glass crystallizes to form an equilibrium texture with a very low porosity (near zero) and ight grain boundaries. Use of a fine particle size for devitrification of the Or glass is critical to produce an equilibrium rather than a spherulitic texture (R. Cooper, pers. comm.).

The product of the oxygen grain boundary diffusion coefficient (D') and the effective grain boundary width $(\delta)$ has been determined for these aggregates. The D' $\delta$ values for the Or and the Ab 
aggregates are similar, and at $600^{\circ} \mathrm{C}$ are approximately a factor of four greater than that for a 4.9 $\mu \mathrm{m}$ novaculite and nearly equal to oxygen diffusion along macroperthite lamellae. The similarity between the D' $\delta$ values obtained for the two different feldspar aggregates indicates that the small amount of porosity remaining in the albite aggregate has no measurable influence on the oxygen grain boundary diffusion rates. This is consistent with our previous observations for quartz aggregates which indicated that it is not simply the presence, but rather the interconnectedness, of the porosity that influences the grain boundary transport rates in fine-grained aggregates. The activation energies for the feldspar aggregates, $\sim 18 \mathrm{kcal} /$ mole, are less than that for the $4.9 \mu \mathrm{m}$ novaculite $(26 \mathrm{kcal} / \mathrm{mole}$ ), and much less than that for macroperthite lamellar boundaries (43 $\mathrm{kcal} /$ mole). The results of this study indicate that these hot-pressed aggregates can provide suitable material for grain boundary diffusion determinations of oxygen, and that the feldspar aggregates should be suitable for cation determinations as well.

\section{Publications Resulting from DOE Sponsored Research}

Farver, J. R. and Yund, R. A., 1990, Oxygen grain boundary diffusion in fine-grained quartz. aggregates, Trans. Am. Geophys. Union EOS, 71, 640.

Yund, R. A. and Farver, J. R., 1990, Oxygen grain boundary diffusion in quartz aggregates: Role of microstructure and fluid composition, Trans. Am. Geophys. Union EOS, 71, 1664.

Farver, J. R. and Yund, R. A., 1991a, Measurement of oxygen grain boundary diffusion in natural fine-grained quartz aggregates, Geochim. Cosmochim. Acta, 55, 1597-1607.

Farver, J. R. and Yund, R. A., 1991b, Oxygen grain boundary diffusion in hot-pressed, finegrained feldspar aggregates, Trans. Am. Geophys. Union EOS, 72, 529.

Farver, J. R. and Yund, R. A., 1992, Oxygen diffusion in a fine-grained quartz aggregate with wetted and nonwetted microstructures, J. Geophys. Res. in press.

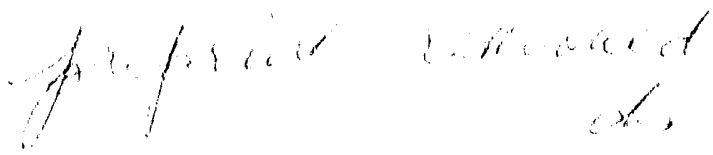



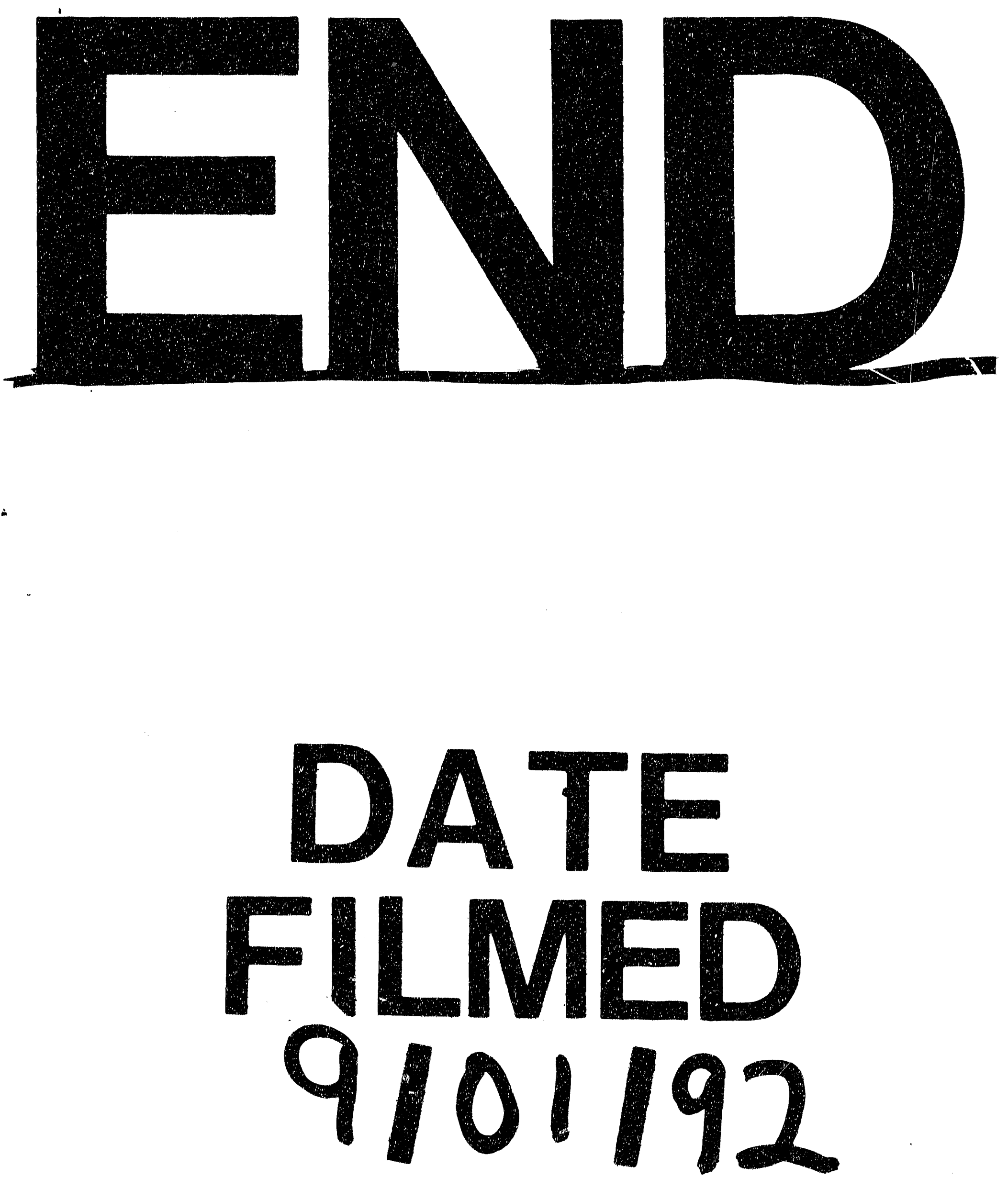
